\begin{tabular}{|c|l|}
\hline Title & $\begin{array}{l}\text { Copper-Catalyzed Enantioselective Coupling between A lly lboronates and Phosphates U sing a Phenol-Carbene Chiral } \\
\text { Ligand: A symmetric Synthesis of Chiral Branched 1,5-Dienes }\end{array}$ \\
\hline Author(s) & Y asuda, Y uto; Ohmiya, Hirohisa; Sawamura, Masay a \\
\hline Citation & $\begin{array}{l}\text { Synthesis stuttgart, 50(11), 2235-2246 } \\
\text { https://doi.org/10.1055/50036-1591548 }\end{array}$ \\
\hline Issue Date & 2018-06 \\
\hline Doc URL & http://hdl.handle.net/2115/74534 \\
\hline Rights & (c)2018 Georg Thieme V erlag KG \\
\hline Type & article (author version) \\
\hline File Information & Synthesis_revision.10.pdf \\
\hline
\end{tabular}

Instructions for use 


\section{Copper-Catalyzed Enantioselective Coupling between Allylboronates and Phosphates with a Phenol-Carbene Chiral Ligand: Asymmetric Synthesis of Chiral Branched 1,5-Dienes}

\author{
Yuto Yasuda ${ }^{a}$ \\ Hirohisa Ohmiya*b \\ Masaya Sawamura*a \\ ${ }^{a}$ Department of Chemistry, Faculty of Science, \\ Hokkaido University, Sapporo 060-0810, Japan \\ sawamura@sci.hokudai.ac.jp \\ ${ }^{\mathrm{b}}$ Division of Pharmaceutical Sciences, Graduate School of \\ Medical Sciences, Kanazawa University, Kakuma-machi, \\ Kanazawa 920-1192, Japan \\ ohmiya@p.kanazawa-u.ac.jp
}

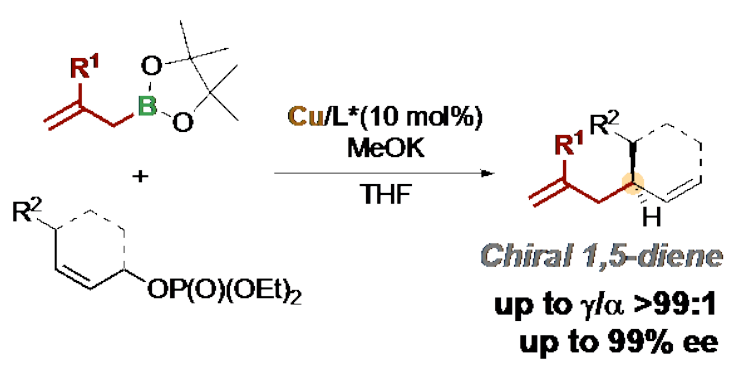

\section{Received: \\ Accepted: \\ Published online: \\ DOI:}

Abstract This report presents details of the Cu-catalyzed enantioselective allyl-allyl coupling reaction between allylboronates and (Z)-allylic phosphates using a new chiral $\mathrm{N}$-heterocyclic carbene (NHC) ligand containing a phenolic hydroxyl group. The copper catalysis delivered enantioenriched chiral 1,5dienes with a tertiary stereogenic center. Various functional group compatibility and the use of earth-abundant and relatively low-toxicity $\mathrm{Cu}$ as a metal were attractive features of this protocol. The utility of the chiral phenol-NHC ligand for enantioselective copper catalysis with organoboron compounds was demonstrated. Enantio-discrimination models were discussed.

Key words asymmetric catalysis · allylic substitution · synthetic method copper catalysis · organoboron

\section{INTRODUCTION AND BACKGROUND}

Chiral 1,5-dienes with a stereogenic center at the allylic/homoallylic position are found in many important biologically active molecules such as FK-506, Plakortide E, and Chaetoglobosin A (Figure 1) ${ }^{[1]}$, and also serve as useful building blocks in organic synthesis due to the versatility of the two alkene functionalities for further transformations. While several methods have been developed to produce chiral 1,5-dienes [2], enantioselective $\gamma$-substitution of allyl alcohol derivatives with organometal reagents (allyl-allyl coupling) using the chiral transition metal complexes as catalysts is the most

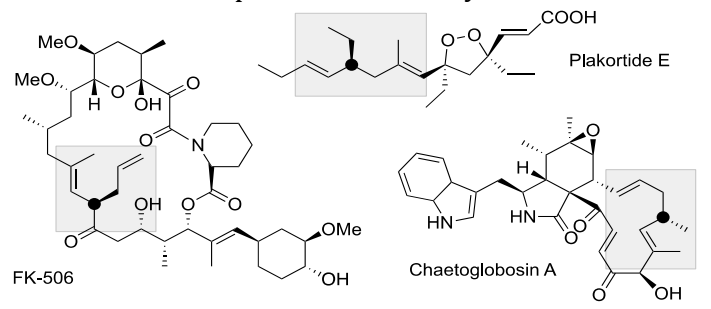

Figure 1. Biologically active compounds straightforward because it uses readily available substrates. ${ }^{[3]}$

In 2010, Morken and co-workers reported the pioneering example of catalytic asymmetric allyl-allyl coupling; Pdcatalyzed allyl-allyl coupling between substituted allylboronates ${ }^{[4]}$ and $(E)$-allylic carbonates occurred with high regio- and enantioselectivity. ${ }^{[5]}$ This protocol enabled access to chiral 1,5-dienes containing contiguous stereogenic centers with high diastereo- and enantioselectivity. More recently, Feringa's group reported asymmetric cross-coupling between allyl Grignard reagents and (E)-allyl bromides using the copperchiral monodentate phosphoramidite catalyst, but only moderate $\mathrm{S}_{\mathrm{N}} 2^{\prime}$ regioselectivity was obtained. ${ }^{[6]}$ In 2014, Carreira et al. developed Ir-catalyzed regio- and enantioselective allylic cross-coupling between allylsilanes and secondary aromatic allylic alcohols. ${ }^{[7]}$ Despite these efforts, the allyl-allyl coupling was limited to use of acyclic $(E)$-allylic electrophiles.

Recently, the $\mathrm{Cu}$-catalyzed enantioselective allyl-allyl coupling between allylboronates and allylic phosphates ${ }^{[8-11]}$ using a new chiral $\mathrm{N}$-heterocyclic carbene (NHC) ligand bearing a phenolic hydroxyl group[12,13] was reported. Reaction occurred with exceptional $\gamma$-regioselectivity and high enantioselectivity. Various functional groups were tolerated. The ability to use (Z)aliphatic allylic substrates in the copper catalysis was complementary to Morken's Pd system (in their reports, only primary (E)-allylic electrophiles were used).[5] The present report describes the details of further studies of this $\mathrm{Cu}-$ catalyzed enantioselective allyl-allyl coupling.[8]

\section{RESULTS AND DISCUSSION}

Optimization. Enantioselective $\mathrm{S}_{\mathrm{N}} 2$ ' allylic alkylation between non-allylic alkylboranes (alkyl-9-BBN) and primary allylic substrates using a catalytic amount of a chiral bisphosphine/ $\mathrm{Cu}(\mathrm{I})$ complex and a stoichiometric amount of potassium alkoxide base has been reported.[14] The results prompted the initiation of a program to develop a Cu-catalyzed enantioselective allylic substitution with allylboron reagents. 
For screening of the reaction conditions, commercially available allylboronic acid pinacolate esters were used instead of the allyl-9-BBN reagents (Table 1).[15] While investigating an effective achiral ligand that could selectively produce the racemic, branched $\gamma$-substitution product (3aa), a ringsaturated NHC/Cu complex prepared in situ from 1,3-bis(2,4,6trimethylphenyl)imidazolinium chloride (SIMes $\cdot \mathrm{HCl}), \mathrm{CuCl}$, and KOMe was produced in high yield (93\%) with exclusive $\gamma$ regioselectivity $(\gamma / \alpha>99: 1)$ to form the branched coupling product 3aa from reaction between 2-allyl-4,4,5,5-tetramethyl1,3,2-dioxaborolane (1a) and $\gamma$-monosubstituted primary (Z)allylic phosphate $2 \mathrm{a}$ in THF at $-20^{\circ} \mathrm{C}$ (entry 1 ). In contrast to the excellent performance of the ring-saturated NHC ligand SIMes, the corresponding unsaturated NHC ligand IMes, derived from 1,3-bis(2,4,6-trimethylphenyl)imidazolium chloride (IMes $\cdot \mathrm{HCl})$, gave a mixture of branched and linear products with a low $\gamma / \alpha$ regioselectivity (62:38) and moderate total product yield (entry 2). Without a ligand, or with 1,10-phenanthroline (Phen) or 1,2bis(diphenylphosphino)ethane (DPPE) ligands, no reaction occurred (entries 3-5). The use of triphenylphosphine $\left(\mathrm{Ph}_{3} \mathrm{P}\right)$ as a monodentate phosphine ligand gave only the linear $\alpha$ substitution product (E)-4aa (entry 6).

Based on these results, focus was placed on ring-saturated chiral NHC ligands (Table 1 , entries 7-14). The $C_{2}$-symmetric imidazolinium chloride $[(S, S)-\mathbf{L 1} \cdot \mathrm{HCl}],{ }^{16]}$ which has two stereogenic carbon centers in the imidazolidine ring with two $\mathrm{N}$ mesityl groups, did not result in enantioselectivity; the branched, nearly racemic coupling product $\mathbf{3 a a}$ was obtained with exclusive regioselectivity and moderate yield (entry 7). When similar chiral NHC ligands (L2, L3) bearing 2-methylphenyl (L2) or 2-methoxyphenyl (L3) groups were used instead of one of the mesityl groups in L1, enantioselectivity was moderate $(50 \%$ and $54 \%$ ee), but yields were low (entries 8 and 9). Next, the imidazolinium salt $\mathbf{L 4} \cdot \mathrm{HBF}_{4}$ bearing a 2-hydroxyphenyl group was used (entry 10). A previous report indicated that L4 exhibited high ligand performance in enantioselective $\mathrm{Cu}$ catalyzed allylic substitution with terminal alkyne as pronucleophiles.[12a] Fortunately, the Cu-L4 catalyst system produced better results; the coupling product was formed in greater yield $(77 \%)$ and with greater enantioselectivity $(85 \%$ ee) compared to the system using $(S, S)$-L2 or $\mathbf{L 3}$, without decreasing regioselectivity. These results indicated that the phenolic hydroxy group in $\mathbf{L} \mathbf{4}$ has a functional role. Changing the $N$-mesityl group of $\mathbf{L 4} \cdot \mathrm{HBF}_{4}$ to a $N$-2,4-dicyclohexyl-6methylphenyl group to afford the new phenol-NHC chiral ligand precursor $\mathbf{L 5} \cdot \mathrm{HBF}_{4}$, resulted in greater enantioselectivity $(92 \%$ ee), a high yield (83\%), and exceptional regioselectivity $(\gamma / \alpha>$ 99:1) (entry 11). Furthermore, the enantioselectivity was achieved $(99 \%$ ee) by decreasing the reaction temperature to $40{ }^{\circ} \mathrm{C}$ (entry 12). In contrast, the naphthol-NHC chiral ligands L6 and $\mathbf{L} \mathbf{7}^{[12 b]}$ were not effective (entries 13 and 14).

Table 1. Ligand effects for reaction between $1 \mathbf{a}$ and $(Z)-2 a^{[a]}$

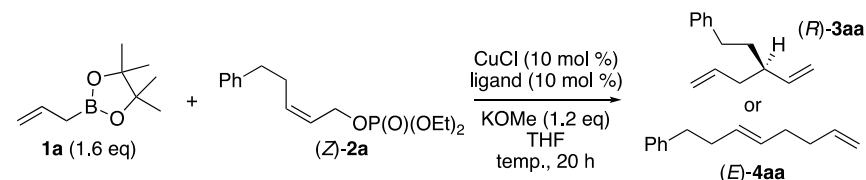

$($ (E)-4aa

\begin{tabular}{lccccc}
\hline Entry & Ligand & $\left.\operatorname{Temp}^{\circ} \mathrm{C}\right)$ & ${\text { Yield }(\%)^{[\mathrm{b}]}}$ & $\gamma / \alpha(\text { 3aa:4aa })^{[\mathrm{c}]}$ & ${\text { Ee }(\%)^{[\mathrm{d}]}}$ \\
\hline 1 & SIMes $\cdot \mathrm{HCl}$ & -20 & 93 & $>99: 1$ & - \\
2 & IMes $\cdot \mathrm{HCl}$ & -20 & 65 & $62: 38$ & - \\
3 & none & -20 & 0 & - & - \\
4 & Phen & -20 & 0 & - & -
\end{tabular}

\begin{tabular}{|c|c|c|c|c|c|}
\hline 5 & DPPE & -20 & 0 & - & - \\
\hline 6 & $\mathrm{PPh}_{3}$ & -20 & 57 & $1:>99$ & - \\
\hline 7 & $(S, S)-\mathbf{L} \mathbf{1} \cdot \mathbf{H C l}$ & -20 & 49 & $>99: 1$ & 2 \\
\hline 8 & $(S, S)-\mathrm{L} 2 \cdot \mathrm{HBF}_{4}$ & -20 & 13 & $>99: 1$ & 50 \\
\hline 9 & $(S, S)-\mathrm{L} \mathbf{3} \cdot \mathrm{HBF}_{4}$ & -20 & 10 & $>99: 1$ & 54 \\
\hline 10 & $(S, S)-\mathrm{L} 4 \cdot \mathrm{HBF}_{4}$ & -20 & 77 & $>99: 1$ & 85 \\
\hline 11 & $(S, S)-\mathbf{L 5} \cdot \mathrm{HBF}_{4}$ & -20 & 83 & $>99: 1$ & 92 \\
\hline $12^{[\mathrm{e}]}$ & $(S, S)-\mathbf{L} \mathbf{5} \cdot \mathrm{HBF}_{4}$ & -40 & 80 & $>99: 1$ & 99 \\
\hline 13 & $(S, S)-\mathrm{L} \cdot \mathrm{HBF}_{4}$ & -20 & 34 & $92: 8$ & 67 \\
\hline 14 & $(S, S)-\mathrm{L} 7 \cdot \mathrm{HBF}_{4}$ & -20 & 56 & $>99: 1$ & 82 \\
\hline
\end{tabular}

[a] Data are taken from ref 8. Conditions: 1a $(0.24 \mathrm{mmol}),(Z)-2 \mathrm{a}(0.15 \mathrm{mmol})$, $\mathrm{CuCl} /$ ligand $(10 \mathrm{~mol} \%), \mathrm{KOMe}(0.18 \mathrm{mmol}), \operatorname{THF}(0.6 \mathrm{~mL})$ for $20 \mathrm{~h}$. [b] Yield of isolated product. [c] Determined by ${ }^{1} \mathrm{H}$ NMR analysis of the crude product. [d] The ee was determined by HPLC. [e] $1 \mathrm{a}(1.9 \mathrm{mmol})$ and $(Z)-2 \mathrm{a}(1.2 \mathrm{mmol})$ were used. Reaction was conducted for $48 \mathrm{~h}$.

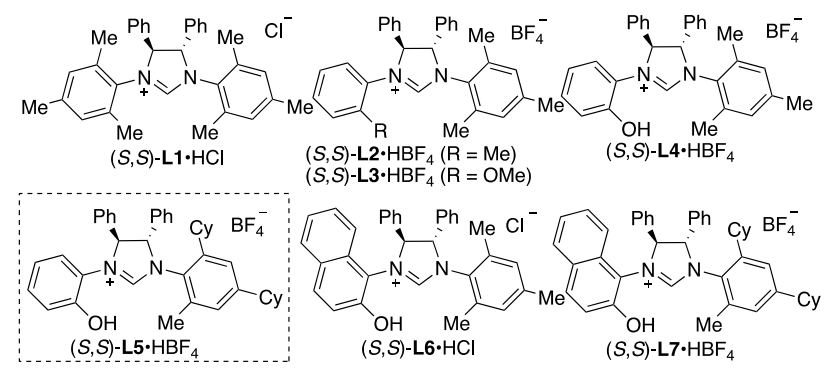

Next, the effect of copper salts (Table 2) was investigated. When CuOAc was used as the catalyst, regioselectivity $(\gamma / \alpha$ 91:9) and enantioselectivity (76\% ee) decreased. The use of $\mathrm{Cu}(\mathrm{OAc})_{2}$ instead of $\mathrm{Cu}(\mathrm{I})$ salt, resulted in a modest yield and low selectivities. Changing $\mathrm{CuCl}$ to $\mathrm{CuOTf} \cdot$ toluene $_{1 / 2}$ afforded similar selectivity but a lower product yield. Use of $\mathrm{MesCu}$ and cationic $\mathrm{Cu}(\mathrm{MeCN})_{4} \mathrm{PF}_{6}$ was as effective as $\mathrm{CuCl}$, and gave comparable results.

The effect of solvent is shown in Table 2. Reaction with toluene gave only the racemic product in moderate yield (43\%) and low regioselectivity $(\gamma / \alpha$ 64:36). Dichloromethane was ineffective in the reaction ( $26 \%$ yield, $\gamma / \alpha 71: 29,51 \%$ ee). No reaction occurred in $\mathrm{MeCN}$ or hexane.

Table 2. Effects of copper salts and solvents ${ }^{[a]}$

\begin{tabular}{clllcl}
\hline Entry & Cu Salt & Solvent & $\begin{array}{l}\text { Yield } \\
(\%)^{[\mathrm{b}]}\end{array}$ & $\begin{array}{c}\gamma / \alpha \square \\
{[(R)-3 a a:(E)-4 a a]^{[c]}}\end{array}$ & $\begin{array}{l}\text { Ee } \\
(\%)^{[\mathrm{d}]}\end{array}$ \\
\hline $1^{\text {[e] }}$ & $\mathrm{CuCl}$ & THF & 83 & $>99: 1$ & 92 \\
2 & $\mathrm{CuOAc}$ & THF & 85 & $91: 9$ & 76 \\
3 & $\mathrm{Cu}(\mathrm{OAc})_{2}$ & THF & 68 & $73: 27$ & 52 \\
4 & $\mathrm{CuOTf} \cdot$ toluene $_{1 / 2}$ & THF & 48 & $>99: 1$ & 90 \\
5 & $\mathrm{MesCu}$ & THF & 85 & $>99: 1$ & 89 \\
6 & $\mathrm{Cu}(\mathrm{MeCN})_{4} \mathrm{PF}_{6}$ & THF & 73 & $>99: 1$ & 88 \\
7 & $\mathrm{CuCl}$ & toluene & 43 & $64: 36$ & 0 \\
8 & $\mathrm{CuCl}$ & DCM & 26 & $71: 29$ & 51 \\
9 & $\mathrm{CuCl}$ & MeCN & 0 & - & - \\
10 & $\mathrm{CuCl}$ & hexane & 0 & - & - \\
\hline
\end{tabular}

[a] Conditions: 1a (0.24 mmol), (Z)-2 (0.15 mmol), Cu salt/(S,S)-L5 $\cdot \mathrm{HBF}_{4}(10 \mathrm{~mol} \%)$, KOMe $(0.18 \mathrm{mmol})$, solvent $(0.6 \mathrm{~mL}),-20^{\circ} \mathrm{C}$ for $20 \mathrm{~h}$. [b] Yield of isolated product. [c] Determined by ${ }^{1} \mathrm{H}$ NMR of crude product. [d] The ee was determined by HPLC. [e] Table 1, entry 11.

The effects of leaving groups and bases are summarized in Table 3. The use of allyl bromide or chloride as an allylic electrophile under the conditions described for Table 1, entry 11, decreased both regio- and enantioselectivity (entries 2 and 3).

The nature of the base had a significant impact on yield and selectivities (Table 3). Use of NaOMe instead of KOMe decreased regioselectivity $(\gamma / \alpha$ 89:11) and enantioselectivity (74\% ee) (entry 4). No reaction occurred with LiOMe, due to the greater 
solubility of $\mathrm{LiCl}$ or $\mathrm{LiOP}(\mathrm{O})(\mathrm{OEt})_{2}$, which may form inactive $\mathrm{Cu}$ species through ionic interactions. (entry 5). The structure of the alkoxide moiety of the base also had a strong impact on yield, regioselectivity, and enantioselectivity. Thus, when KOMe was changed to a sterically more demanding base, $\mathrm{KO} t \mathrm{Bu}$, product yield was moderate and both regioselectivity and enantioselectivity decreased significantly (entry 6). This result suggests that the trialkoxyboron ROBpin may participate in the reaction because Lewis acids activate the phosphate leaving group (see Figure 4). Coupling reaction with $\mathrm{K}_{2} \mathrm{CO}_{3}$ did not occur (entry 7).

Table 3. Effect of leaving group and base ${ }^{[a]}$

\begin{tabular}{clllcl}
\hline Entry & Leaving group & Base & $\begin{array}{l}\text { Yield } \\
(\%)^{[b]}\end{array}$ & $\begin{array}{c}\gamma / \alpha \square \\
{[(R)-3 a a:(E)-4 a a]^{[c]}}\end{array}$ & $\begin{array}{l}\text { Ee } \\
(\%)^{[d]}\end{array}$ \\
\hline $1^{[\mathrm{e}]}$ & $\mathrm{OP}(\mathrm{O})(\mathrm{OEt})_{2}(2 \mathrm{a})$ & KOMe & 83 & $>99: 1$ & 92 \\
2 & $\mathrm{Cl}^{[\mathrm{f}]}$ & KOMe & 89 & $94: 6$ & 64 \\
3 & $\mathrm{Br}^{[\mathrm{g}]}$ & KOMe & 85 & $82: 18$ & 20 \\
4 & $\mathrm{OP}(\mathrm{O})(\mathrm{OEt})_{2}(2 \mathrm{a})$ & $\mathrm{NaOMe}$ & 91 & $89: 11$ & 74 \\
5 & $\mathrm{OP}(\mathrm{O})(\mathrm{OEt})_{2}(2 \mathrm{a})$ & $\mathrm{LiOMe}$ & 0 & - & - \\
6 & $\mathrm{OP}(\mathrm{O})(\mathrm{OEt})_{2}(2 \mathrm{a})$ & $\mathrm{KOtBu}$ & 67 & $63: 37$ & 50 \\
7 & $\mathrm{OP}(\mathrm{O})(\mathrm{OEt})_{2}(2 \mathrm{a})$ & $\mathrm{K}_{2} \mathrm{CO}_{3}$ & 0 & - & - \\
\hline
\end{tabular}

[a] Data are taken from ref 8 . Conditions: $1 \mathbf{a}(0.24 \mathrm{mmol}),(Z)-2(0.15 \mathrm{mmol}), \mathrm{CuCl} /$ $(S, S)-\mathrm{L} 5 \cdot \mathrm{HBF}_{4}(10 \mathrm{~mol} \%)$, base $(0.18 \mathrm{mmol}), \mathrm{THF}(0.6 \mathrm{~mL}),-20{ }^{\circ} \mathrm{C}$ for $20 \mathrm{~h}$. [b] Yield of isolated product. [c] Determined by ${ }^{1} \mathrm{H}$ NMR of crude product. [d] The ee was determined by HPLC. [e] Table 1, entry 11. [f] (Z)-(5-Chloro-3-penten-1-yl)benzene. [g] (Z)-(5-Bromo-3-penten-1-yl)benzene.

Substrate Scopes. (Z)-Allylic phosphates with various aliphatic substituents were reacted with $\mathbf{1 a}$ in the $\mathbf{C u}-\mathbf{L} \mathbf{5}$ catalyst system (Table 4). When the 2-phenylethyl group of 2a was replaced with a benzyl or octyl group, coupling proceeded with excellent $\gamma$-selectivity and preservation of enantioselectivity (entries 1 and 3). A sterically more demanding $\gamma$-substituent, such as a cyclohexyl group, was also tolerated and produced a high level of enantioselectivity $(80 \%$ ee) (entry 4).[17] Notably, the enantioselective reaction with 2-butene-1,4-diol derivatives, which have two potential leaving groups at different allylic positions, occurred with the allylic $\mathrm{C}-\mathrm{O}$ bonds in the ether or carboxylic ester leaving groups untouched (entries 5-12 and 15).

The reaction has a great functional group compatibility (entries 2 and 5-12, 15-17). For example, an allylic phosphate (2) bearing a 1,3-benzodioxole (2c), THP ether (2f), benzyl ether (2g), silyl ether $(\mathbf{2 h}, \mathbf{q}),{ }^{[17]}$ pivalate (2i), carbamate $(\mathbf{2} \mathbf{p})$ or $p$-toluenesulfonate (2r) group as the aliphatic $\gamma$-substituent, reacted with $\mathbf{1 a}$ to produce the corresponding 1,5-diene derivatives in good yields with high enantioselectivities (8597\% ee) (entries 2, 5-8, 15-17). Methoxy, trifluoromethyl, bromo, or dimethylamino substituents were tolerated in the aromatic ring of the benzoate groups (entries 9-12). However, no reaction occurred with the allylic phosphate bearing a nitro (2n) or cyano (2o) group (entries 13 and 14).

The potential for scaling up the enantioselective allyl-allyl coupling was examined on a preparative scale (Eq. 1). Reaction between allylboronate 1a $(9.4 \mathrm{mmol}, 1.5 \mathrm{~g})$ and allylic phosphate $2 \mathrm{~h}$ (5.9 mmol, $2.0 \mathrm{~g}$ ) afforded only the branched coupling product in $73 \%$ yield $(0.98 \mathrm{~g}, 4.3 \mathrm{mmol})$ with $92 \%$ ee.

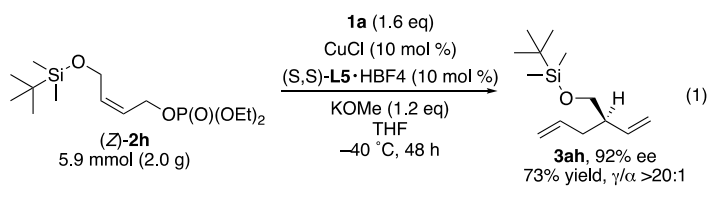

Table 4. Scope of allylic phosphates ${ }^{[a]}$

\begin{tabular}{|c|c|c|c|c|c|}
\hline Entry & $\begin{array}{c}\text { Phosphate } \\
\mathrm{OP}=\mathrm{OP}(\mathrm{O})(\mathrm{OEt})_{2}\end{array}$ & Product & $\begin{array}{l}\text { Temp } \\
\left({ }^{\circ} \mathrm{C}\right)\end{array}$ & $\begin{array}{l}\text { Yield } \\
(\%)^{[b, c]}\end{array}$ & $\begin{array}{l}\mathrm{Ee} \\
(\%)^{[\mathrm{d}]}\end{array}$ \\
\hline 1 & & & -50 & 62 & 86 \\
\hline 2 & 2c & & -30 & 97 & 86 \\
\hline 3 & & & -40 & 85 & 84 \\
\hline 4 & & & -50 & 59 & 80 \\
\hline 5 & $R=\operatorname{THP}(\mathbf{2 f})$ & 3af & -30 & 83 & 90 \\
\hline 6 & $\mathrm{R}=\mathrm{Bn}(2 \mathrm{~g})$ & 3ag & -50 & 75 & 85 \\
\hline 7 & $\mathrm{R}={ }^{t} \mathrm{BuMe}_{2} \mathrm{Si}(\mathbf{2 h})$ & 3ah & -50 & 78 & 97 \\
\hline 8 & $R=\operatorname{Piv}(\mathbf{2 i})$ & 3ai & -30 & 70 & 91 \\
\hline 9 & $\mathrm{R}=\mathrm{MeO}(\mathbf{2} \mathbf{j})$ & 3aj & -30 & 85 & 92 \\
\hline 10 & $\mathrm{R}=\mathrm{F}_{3} \mathrm{C}(\mathbf{2} \mathbf{k})$ & 3ak & -30 & 61 & 90 \\
\hline 11 & $\mathrm{R}=\mathrm{Br}(\mathbf{2 I})$ & 3al & -30 & 65 & 90 \\
\hline 12 & $\mathrm{R}=\mathrm{Me}_{2} \mathrm{~N}(\mathbf{2 m})$ & 3am & -30 & 87 & 91 \\
\hline 13 & $\mathrm{R}=\mathrm{NO}_{2}(\mathbf{2 n})$ & 3an & -10 & 0 & - \\
\hline 14 & $\mathrm{R}=\mathrm{CN}(\mathbf{2 0})$ & 3 ao & -10 & 0 & - \\
\hline 15 & & & -30 & 80 & 90 \\
\hline 16 & & & -40 & 78 & 96 \\
\hline 17 & & & -30 & 88 & 92 \\
\hline
\end{tabular}

[a] Data are taken from ref 8 for entries 1-12 and 15-17. Conditions: 1a (0.24 $\mathrm{mmol}),(Z)-2(0.15 \mathrm{mmol}), \mathrm{CuCl} /(\mathrm{S}, \mathrm{S})-\mathrm{L} 5 \cdot \mathrm{HBF}_{4}(10 \mathrm{~mol} \%), \mathrm{KOMe}(0.18 \mathrm{mmol}), \mathrm{THF}$ $(0.6 \mathrm{~mL})$ for $48 \mathrm{~h}$. [b] Yield of isolated product. [c] Constitutional isomer ratio $\gamma / \alpha$ $>$ 20:1 (determined by ${ }^{1}$ H NMR of crude product). [d] The ee was determined by HPLC.

The copper-catalyzed allyl-allyl coupling reaction between $\mathbf{1 a}$ and enantioenriched 2-butene-1,4-diol derivative $(S)$-2s $(99 \%$ ee) with $(R, R)$-L5 $\cdot \mathrm{HBF}_{4}$ (i.e., an enantiomeric isomer of $(S, S)$ L5 $\mathrm{HBF}_{4}$ ) gave the corresponding 1,5-diene 3as with two adjacent stereogenic centers with a $2 S, 3 S$-configuration in modest yield (51\%) and high diastereoselectivity (d.r. 90:10) (Eq. 2). Without a ligand, or with $(S, S)-\mathbf{L} \mathbf{5} \cdot \mathrm{HBF}_{4}$, the reaction gave no or only a trace of the coupling product. Thus, the use of $\mathbf{L 5}$ is mandatory, and $(R, R)$ - L5-Cu system and the $(S)$-2s substrate is a matched pair, while $(S, S)$-L5/Cu complex and $(S)$ $2 \mathbf{s}$ is mismatched. This result is in accord with a consideration of the Felkin-Anh model as depicted in Figure 2, which predicts preferred approach of organocopper nucleophile to $\mathrm{Si}$-face of the allylic plain with a minimum $A^{1,3}$-strain. 

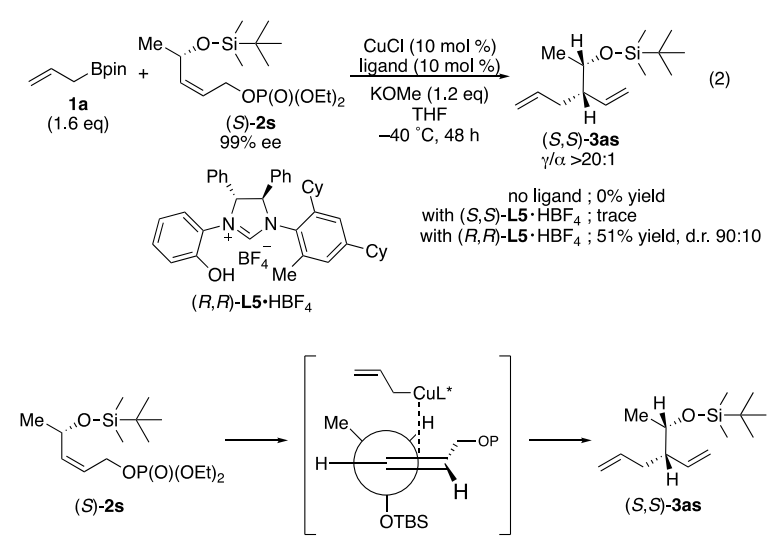

Figure 2. A Felkin-Anh-type stereoselection model

Reactions of $\beta$-substituted allylboronate derivatives using the Cu-L5 catalyst system were investigated (Table 5). Methallylboronate 1b and 2-ethyl-2-propen-1-ylboronate 1c reacted with (Z)-2a with excellent $\gamma$-selectivity $(\gamma / \alpha>20: 1)$ and high enantioselectivity ( $95 \%$ and $80 \%$ ee, respectively) (entries 1 and 2). An allylboronate with a hexyl, benzyl, or phenyl group at the $\beta$-position (1d-f) underwent reaction to afford the coupling products with enantiomeric excesses greater than $80 \%$, while the regioselectivities were moderate (entries 3-5).[18] The allylboronate with a chloro group at the $\beta$-position did not react (entry 6). In addition, no reaction occurred with $\gamma$-substituted allylboronates such as trans- or cis-crotylboronates.

Table 5. Scope of allylboronates ${ }^{[a]}$

Entry Allylboronate $\begin{gathered}\begin{array}{c}\text { Phosphate } \\ \mathrm{OP}=\mathrm{OP}(\mathrm{O})(\mathrm{OEt})_{2}\end{array} \\ \text { Product }\end{gathered}$

[a] Data are taken from ref 8 for entries 1-5. Conditions: $1(0.24 \mathrm{mmol}),(Z)-2$ (0.15 mmol), $\mathrm{CuCl} /(\mathrm{S}, \mathrm{S})-\mathrm{L} 5 \cdot \mathrm{HBF}_{4}(10 \mathrm{~mol} \%), \mathrm{KOMe}(0.18 \mathrm{mmol}), \mathrm{THF}(0.6 \mathrm{~mL}),-50$ ${ }^{\circ} \mathrm{C}$ (entry 1) or $-30{ }^{\circ} \mathrm{C}$ (entries 2-6) for $48 \mathrm{~h}$. [b] Yield of isolated product. [c] Determined by ${ }^{1} \mathrm{H}$ NMR of crude product. [d] The ee was determined by HPLC.

The coupling reaction between $1 \mathrm{a}$ and cis-4-cyclopentene1,3-diol diphosphate $\mathbf{2 u}$ catalyzed by the Cu-L5 system occurred with adequate enantioselectivity, giving the trans-1,2-isomer 3au (Eq. 3).[17,19] Reaction with cis-4-cyclohexene-1,3-diol derivative $2 \mathbf{v}$ gave the trans-1,2-isomer 3av with moderate enantiocontrol (66\% ee) (Eq. 4). These stereochemical results indicate that the present $\mathrm{Cu}$-catalyzed reaction proceeded through an anti-S $\mathrm{S}_{\mathrm{N}}$ ' type reaction pathway. Morken's Pdcatalyzed protocol has not been applied to this type of cyclic allylic electrophile involving a $Z$ alkene moiety. ${ }^{[5]}$

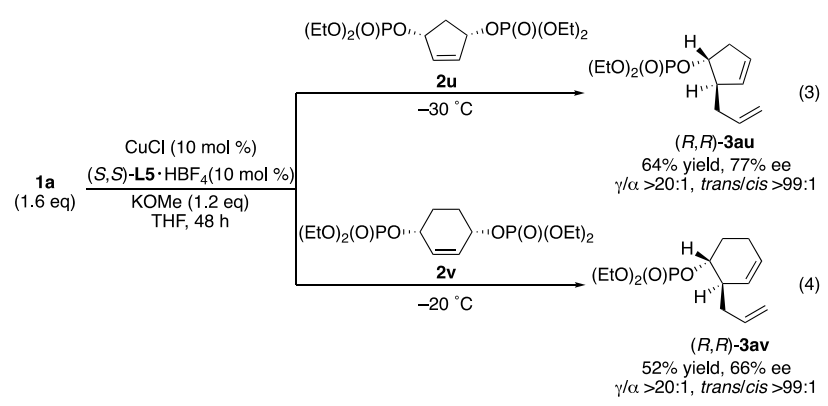

Mechanistic Study and Proposed Reaction Pathway. The alkene geometry of the allylic phosphates influenced both regioand enantioselectivity. Thus, reaction between 1a and $(E)-\mathbf{2 a}$ under the conditions described in Table 1, entry 11 gave the linear $\alpha$-substitution product $(E)$-4aa preferentially with minor formation of $(S)$-3aa $(71 \%$ ee), the antipode of the product derived from (Z)-2a (Eq. 5).[19] This $\alpha$-selectivity appeared to occur via allylic 1,3-migration of $\mathrm{Cu}$ in the allylcopper(III) species. To gain insight into the nature of the postulated allylcopper(III) species, secondary allylic phosphate $\mathbf{2 a}$ ', a constitutional isomer of $(Z)-\mathbf{2 a}$, was reacted under the same conditions (Eq. 6). [19] Interestingly, this reaction gave results similar to reaction with $(E)-\mathbf{2 a}$. The convergence observed in the regioselectivity and stereochemistry suggests that $(E)-\mathbf{2 a}$ and 2a' led to a common equilibrium mixture of the allylcopper(III) species prior to reductive elimination to form the product mixture (Figure 3).[20]
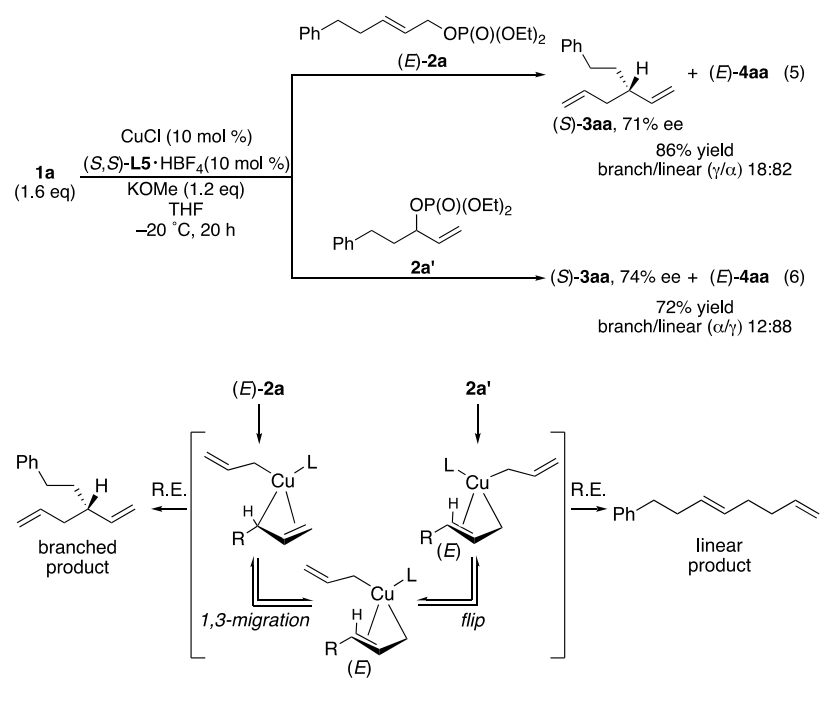

Figure 3. Allylcopper(III) species

Based on the assumption that $\gamma$-selective reaction of $(Z)-2$ also occurs via allylcopper(III) intermediates, a catalytic cycle was proposed for the enantioselective allyl-allyl coupling catalyzed by the Cu-L5 system, as shown in Figure 4.[20] An alkoxycopper(I) complex (A) was formed from reaction between $\mathrm{CuCl}, \mathbf{L 5} \cdot \mathrm{HBF}_{4}$, and $\mathrm{KOMe}$. For this complex, the chiral NHC ligand coordinated to $\mathrm{Cu}$ as an anionic C,O-bidentate ligand. Then, transmetallation between $\mathbf{A}$ and an allylborate (B) ${ }^{[21]}$ afforded the potassium phenoxo(allyl)cuprate (C). Compound $\mathbf{C}$ formed a $\pi$-complex (D) with the allylic phosphate 2 , in which the $\mathrm{Cu}$ was anti to the phosphate leaving group. The MeOBpin may activate the phosphate group as a Lewis acid..[14d] Subsequently, oxidative addition produced ( $\pi$-en- $\sigma$ yl)copper(III) complex E1 with a secondary $\mathrm{sp}^{3}$-carbon atom bound to $\mathrm{Cu}$. Facile reductive elimination of E1, which was faster than allylic 1,3-Cu-migration to form E2, produced the 
branched $\gamma$-substitution product $\mathbf{3}$ and regenerated alkoxycopper(I) complex A (Figs. 5 and 6 for enantiodiscrimination models).

Thus, the crucial dependence of regioselectivity on the $E / Z$ geometry of the allylic substrate (2) can be explained by the greater instability of the allylcopper(III) intermediate E2 compared to the corresponding $\mathrm{Cu}(\mathrm{III})$ species (E1) produced from the $E$ substrate, due to larger steric repulsion in the allyl moiety derived from the $Z$ substrate (Fig. 3). Similar consideration may be applicable to the corresponding transition states that determine the $E / Z$-isomeric product distribution.

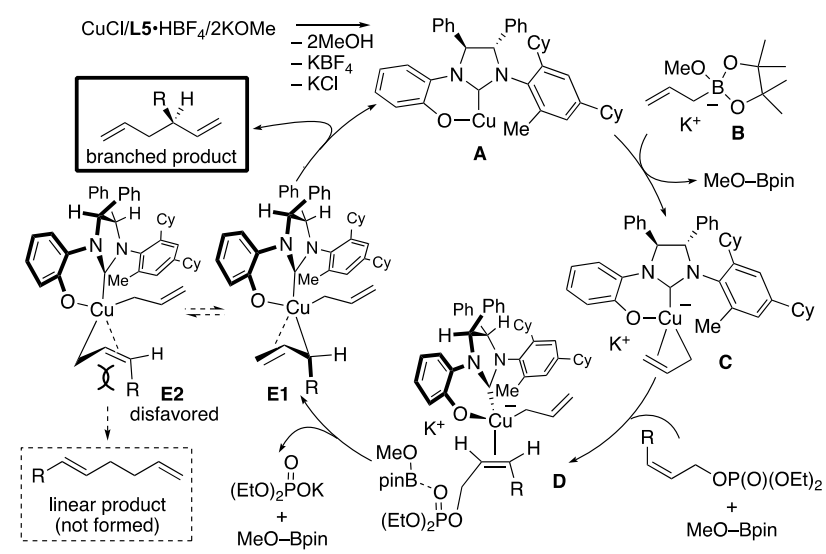

Figure 4. Postulated catalytic reaction pathway.

Reactions of $E$ - and $Z$-isomers of 2a gave the antipodes of 3aa, (Table 1, entry 11 vs. Eq. 5), and the products from (Z)-2a were produced with greater enantioselectivity. This led to the proposal of the enantioselection models shown in Figs. 5 and 6 . In the $\pi$-complex D (Fig. 4), the chiral copper center adopted a tetrahedral coordination geometry including the $\mathrm{C}, \mathrm{O}$-bidentate chelation. The $\mathrm{K}^{+}$ion bridged the phenoxide oxygen and $\mathrm{MeO}-$ Bpin, which interacted with the phosphate leaving group as a Lewis acid. These assumptions suggest four possible $\pi$ complexes (D1 and D2 for the major enantiomer; D3 and D4 for the minor enantiomer) (Fig. 5). Complex D1 is the most favorable, because it results in the fewest steric repulsions between catalyst and allylic phosphate. Complexes D2, D3, and D4 appear to be destabilized by the steric repulsions between the $\gamma$-substituent (R) and nonhydroxylated $N$-aryl group or one of the phenyl groups on the imidazolidine ring. These conclusions are consistent with the experimental observations that the enantioselectivity is influenced by the steric nature of the $\gamma$-substituent (R) (Table 4, entries 3 and 4) or the nonhydroxylated $\mathrm{N}$-aryl group in the phenolic NHC ligands (Table 1 , entries 10 and 11).

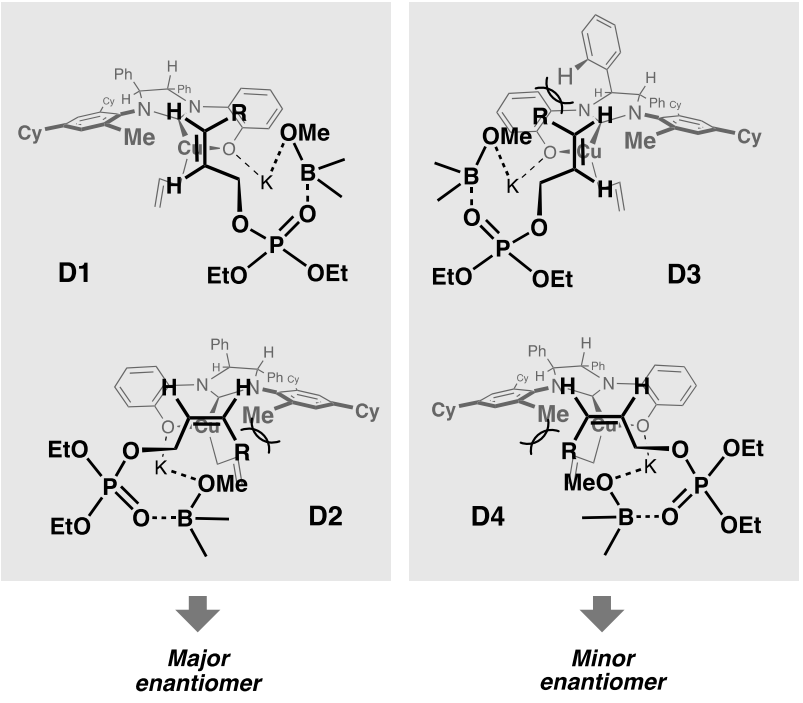

Figure 5. Models for enantioselection with (Z)-2

For reaction of $(E)-2$ (Fig. 6), the nonhydroxylated $N$-aryl group and/or the phenyl group in the imidazolidine ring caused steric repulsion toward the $\gamma$-substituent (R) for all postulated complexes D1'-D4'. These considerations explain the more efficient enantioselection in the reaction with allylic substrates having the $Z$-configuration.
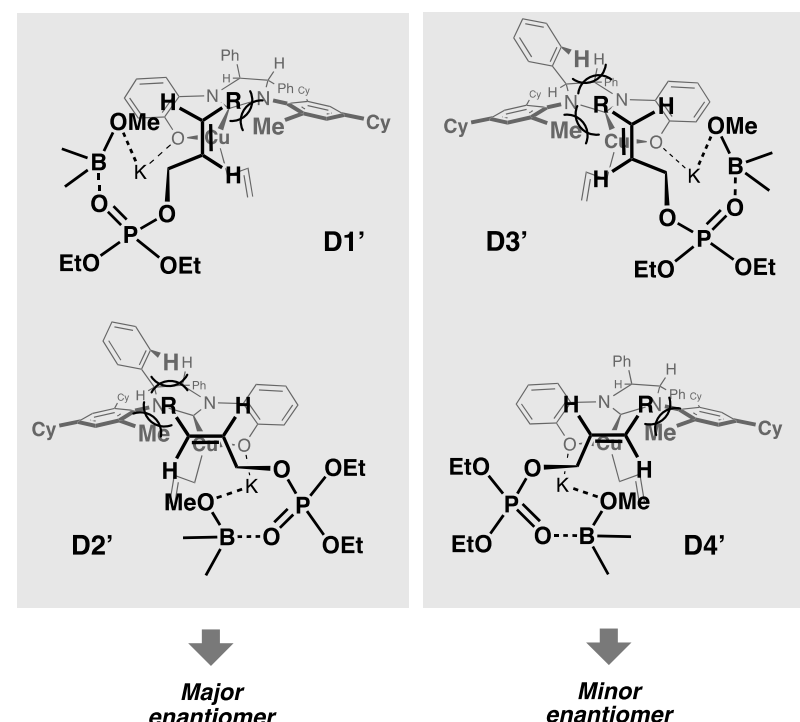

Figure 6. Models for enantioselection with $(E)-2$

\section{CONCLUSIONS}

In conclusion, a versatile method was developed for $\mathrm{Cu}-$ catalyzed enantioselective allyl-allyl coupling between allylboronates and (Z)-acyclic and cyclic allylic phosphates to form various chiral 1,5-diene derivatives. Catalysis of a $\mathrm{Cu}(\mathrm{I})$ complex with a new phenol-NHC chiral ligand enabled the reaction, demonstrating the utility of this class of chiral ligands for enantioselective copper catalysis with organoboron compounds.[12] This Cu-catalyzed protocol provides efficient access to functionalized, enantio-enriched chiral 1,5-dienes with a stereogenic carbon center at the allylic/homoallylic position. The broad functional group compatibility and the use of earthabundant and relatively low-toxic $\mathrm{Cu}$ as a metal are attractive features of this protocol. A functional role for the phenolic 
hydroxy group in the chiral NHC ligand was suggested by the results.

\section{EXPERIMENTAL SECSION}

\section{Instrumentation and Chemicals}

NMR spectra were recorded on a JEOL ECX-400, operating at $400 \mathrm{MHz}$ for ${ }^{1} \mathrm{H}$ NMR, $100.5 \mathrm{MHz}$ for ${ }^{13} \mathrm{C}$ NMR and $128 \mathrm{MHz}$ for ${ }^{11} \mathrm{~B}$ NMR. Chemical shift values for ${ }^{1} \mathrm{H}$ and ${ }^{13} \mathrm{C}$ are referenced to $\mathrm{Me}_{4} \mathrm{Si}$ and the residual solvent resonances, respectively. Chemical shifts are reported in $\delta \mathrm{ppm}$. Mass spectra were obtained with Thermo Fisher Scientific Exactive, JEOL JMS-T100LP or JEOL JMS-700TZ at the Instrumental Analysis Division, Global Facility Center, Creative Research Institution, Hokkaido University. HPLC analyses were conducted on a HITACHI ELITE LaChrom system with a HITACHI L-2455 diode array detector or a HITACHI Chromaster with a HITACHI 5430 diode array detector. Optical rotations were measured on a JASCO P-2200. TLC analyses were performed on commercial glass plates bearing 0.25 -mm layer of Merck Silica gel $60 \mathrm{~F}_{254}$. Silica gel (Kanto Chemical Co., Silica gel $60 \mathrm{~N}$, spherical, neutral) was used for column chromatography. IR spectra were measured with a Perkin-Elmer Spectrum One. Melting points were measured on a Yanaco MP-500D apparatus. Gel permeation chromatography (GPC) was performed by LC-908 (Japan Analytical Industry Ltd., two in-line JAIGEL$2 \mathrm{H}, \mathrm{CHCl}_{3}, 3.5 \mathrm{~mL} / \mathrm{min}$, UV and RI detectors).

All reactions were carried out under nitrogen or argon atmosphere. Materials were obtained from commercial suppliers or prepared according to standard procedures unless otherwise noted. $\mathrm{CuCl}$, and KOMe were purchased from Aldrich Chemical Co., stored under nitrogen, and used as received. THF was purchased from Kanto Chemical Co., and stored under argon. 2-Allyl-4,4,5,5-tetramethyl-1,3,2-dioxaborolane (1a) was obtained from commercial suppliers. Allylboronates $1 \mathrm{~g}$ were prepared according to the reported procedures. ${ }^{[22]}$ Allylboronates $\mathbf{1 b}-\mathbf{f}$ allylic phosphates 2a-r, 2t-v, 2a' and NHC ligands L2-7 were reported in the literature. ${ }^{[8,12 a]}(E)$-4aa are found in the literature. ${ }^{[3]}$

\section{Preparation of Allylic Phosphate (S)-2s}

(S)-3-Butyn-2-ol (99\% ee) $(1.2 \mathrm{~mL}, 15 \mathrm{mmol})$ and imidazole $(2.0 \mathrm{~g}, 30$ mmol) were dissolved in DCM $(30 \mathrm{~mL})$ at $0{ }^{\circ} \mathrm{C}$. Then, TBDMSCl $(3.4 \mathrm{~g}, 22$ mol) was added to the mixture, and the solution was stirred at rt for $8 \mathrm{~h}$. The reaction was quenched with $\mathrm{H}_{2} \mathrm{O}$ and extracted with DCM $(15 \mathrm{~mL} \times$ 3). The combined organic layer was dried over $\mathrm{MgSO}_{4}$. Then, the drying agent was removed by filtration, and a filtrate was evaporated under reduced pressure. A residue was purified by flash chromatography on silica gel $(0-5 \%$ EtOAc/hexane) to give TBDMS-protected alcohol derivative $(2.6 \mathrm{~g}, 14 \mathrm{mmol})$ in $96 \%$ yield.

${ }^{n}$ BuLi $(9.6 \mathrm{~mL}, 15.8 \mathrm{mmol})$ was dropped to a solution of TBDMSprotected alcohol $(2.6 \mathrm{~g}, 14 \mathrm{mmol})$ in $\mathrm{Et}_{2} \mathrm{O}(29 \mathrm{~mL})$ at $-78{ }^{\circ} \mathrm{C}$. The reaction mixture was stirred for $30 \mathrm{~min}$ before formaldehyde $(877 \mathrm{mg}$, $29.2 \mathrm{mmol}$ ) was added to the mixture. The reaction vessel was removed from a cooling bath. After stirring at $\mathrm{rt}$ for 12 hours, the reaction was quenched with $\mathrm{H}_{2} \mathrm{O}$. The mixture was diluted with $\mathrm{Et}_{2} \mathrm{O}$ and the organic layer was separated. The aqueous phase was extracted with $\mathrm{Et}_{2} \mathrm{O}$ (15 $\mathrm{mL} \times 2$ ) and the combined organic layer was washed with brine, dried over $\mathrm{MgSO}_{4}$, filtered, and concentrated under reduced pressure by rotary evaporation. Purification by flash chromatography on silica gel $(0-10 \%$ EtOAc/hexane) afforded the corresponding propargyl alcohol (2.3 g, 10 $\mathrm{mmol}$ ) in $73 \%$ yield.

A solution of propargylic alcohol $(1.1 \mathrm{~g}, 5 \mathrm{mmol})$ in hexane $(4.3$ $\mathrm{mL}) /$ acetone $(790 \mu \mathrm{L})$ was added to the mixture of $\mathrm{Pd} / \mathrm{CaCO}_{3}(40.0 \mathrm{mg})$ and quinoline $(397 \mu \mathrm{L}, 3.6 \mathrm{mmol})$, and then the reaction mixture was filled with hydrogen gas. After confirming the completion of the reaction by ${ }^{1} \mathrm{H}$ NMR, $\mathrm{Pd} / \mathrm{CaCO}_{3}$ was removed by filtration, and the resulting solution was evaporated under reduced pressure. The residue was purified by flash chromatography on silica gel $(0-10 \%$ EtOAc/hexane) to give $(S, Z)-4$-[(tert-butyldimethylsilyl)oxy]-2-penten-1-ol in $80 \%$ yield ( $874 \mathrm{mg}, 4.0 \mathrm{mmol}$ ).

To a solution of $(S, Z)-4$-[(tert-butyldimethylsilyl)oxy]-2-penten-1-ol $(874 \mathrm{mg}, 4.0 \mathrm{mmol})$ in pyridine $(6.1 \mathrm{~mL}),(\mathrm{EtO}){ }_{2} \mathrm{P}(0) \mathrm{Cl}(697 \mu \mathrm{L}, 4.8$ mmol) and DMAP (24 mg, $0.2 \mathrm{mmol})$ were sequentially added at $0{ }^{\circ} \mathrm{C}$. After being stirred at $\mathrm{rt}$ for $3 \mathrm{~h}$, the reaction mixture was diluted with EtOAc $(20 \mathrm{~mL})$ and was treated with $\mathrm{H}_{2} \mathrm{O}(2 \mathrm{~mL})$. The resulting mixture was washed with saturated $\mathrm{CuSO}_{4}$ aq. $(10 \mathrm{~mL} \times 3)$ and brine, dried over anhydrous $\mathrm{MgSO}_{4}$, filtered, and evaporated under reduced pressure. The residue was purified through flash column chromatography on silica gel $(10-45 \%$ EtOAc/hexane) to provide $(S, Z)-4-[($ tertbutyldimethylsilyl)oxy]-2-penten-1-yl diethyl phosphate (2s) in $94 \%$ yield (1.3 g, $3.8 \mathrm{mmol})$. The ee value of $(S)$-2s (99\% ee) was determined by chiral HPLC analysis of the $p$-OMe-benzoate derivative of $(S, Z)-4$ [(tert-butyldimethylsilyl)oxy]-2-penten-1-ol (CHIRALCEL ${ }^{\circledR}$ OD-3 column, $4.6 \mathrm{~mm} \times 250 \mathrm{~mm}$, Daicel Chemical Industries, hexane/2-propanol 99:1, $0.5 \mathrm{~mL} / \mathrm{min}, 40^{\circ} \mathrm{C}, 220 \mathrm{~nm} \mathrm{UV}$ detector, retention time $=13.7 \mathrm{~min}$, for $R$ isomer and $17.7 \mathrm{~min}$ for $S$ isomer).

\section{Characterization Data for Allylic Phosphate} (S,Z)-4-[(tert-Butyldimethylsilyl)oxy]-2-penten-1-yl phosphate (2s) (99\% ee)

Colorless Oil. IR (neat) 667, 775, 830, 975, 1026, 1254, 1369, 1393, 1473, 2858, 2930, 2957 $\mathrm{cm}^{-1} .{ }^{1} \mathrm{H}$ NMR $\left(400 \mathrm{MHz}, \mathrm{CDCl}_{3}\right) \delta 0.04(\mathrm{~s}, 3 \mathrm{H})$, $0.06(\mathrm{~s}, 3 \mathrm{H}), 0.89(\mathrm{~s}, 9 \mathrm{H}), 1.20(\mathrm{~d}, J=6.4 \mathrm{~Hz}, 3 \mathrm{H}), 1.34(\mathrm{t}, J=7.2 \mathrm{~Hz}, 6 \mathrm{H})$, 4.11 (quintet, $J=7.2 \mathrm{~Hz}, 4 \mathrm{H}), 4.55-4.69(\mathrm{~m}, 3 \mathrm{H}), 5.48(\mathrm{dt}, J=11.2,6.0 \mathrm{~Hz}$, $1 \mathrm{H}), 5.64(\mathrm{dd}, J=11.2,8.0 \mathrm{~Hz}, 1 \mathrm{H}) .{ }^{13} \mathrm{C}$ NMR $\left(100 \mathrm{MHz}, \mathrm{CDCl}_{3}\right) \delta-4.8,-4.6$, $16.1(\mathrm{~d}, J=6.7 \mathrm{~Hz}), 18.1,24.6,25.7,63.0(\mathrm{~d}, J=4.8 \mathrm{~Hz}), 63.7(\mathrm{~d}, J=5.7 \mathrm{~Hz})$, 65.1, $122.3(\mathrm{~d}, J=6.6 \mathrm{~Hz}), 139.2$. HRMS-ESI $(\mathrm{m} / \mathrm{z})$ : $[\mathrm{M}+\mathrm{Na}]^{+}$calcd for $\mathrm{C}_{15} \mathrm{H}_{33} \mathrm{O}_{5} \mathrm{NaPSi}, 375.17271$; found, 375.17227. $[\alpha]_{\mathrm{D}}{ }^{25}+150\left(c 1.17, \mathrm{CHCl}_{3}\right)$.

\section{Procedure for the Copper-Catalyzed Enantioselective Allyl-Allyl Coupling}

The reaction in Table 4, entry 1 is representative. $\mathrm{CuCl}(1.5 \mathrm{mg}, 0.015$ mmol), $\mathbf{L 5} \bullet \mathrm{HBF}_{4}(9.8 \mathrm{mg}, 0.015 \mathrm{mmol}$ ) and KOMe (12.6 mg, $0.18 \mathrm{mmol})$ were placed in a vial containing a magnetic stirring bar. The vial was sealed with a Teflon ${ }^{\circledR}$-coated silicon rubber septum, and then the vial was evacuated and filled with argon. THF $(0.6 \mathrm{~mL})$ was added to the vial, and then the mixture was stirred at room temperature for $30 \mathrm{~min}$. Next, 2-allyl-4,4,5,5-tetramethyl-1,3,2-dioxaborolane (1a) $\quad \begin{array}{llll}45.3 & \mu \mathrm{L} & 0.24\end{array}$ mmol) was added. Finally, allylic phosphate $2 \mathbf{b}(42.6 \mathrm{mg}, 0.15 \mathrm{mmol})$ was added at $-50^{\circ} \mathrm{C}$. After $48 \mathrm{~h}$ stirring at $-50^{\circ} \mathrm{C}$, the reaction was quenched with saturated $\mathrm{NH}_{4} \mathrm{Cl}$ aq. and extracted with diethyl ether (1 $\mathrm{mL} \times 3$ ). The combined organic layer was dried over $\mathrm{MgSO}_{4}$. Then, the drying agent was removed by filtration, and the resulting solution was evaporated under reduced pressure. The residue was purified by flash chromatography on silica gel (hexane) to give $\mathbf{3 a b}(15.9 \mathrm{mg}, 0.09 \mathrm{mmol})$ in $62 \%$ yield.

\section{Characterization Data for Allyl-Allyl Coupling Products}

Full details for compounds 3aa-am, 3ap-ar, 3ba-ea, 3ft and 3au-av can be found in our previous report. ${ }^{[8]}$

\section{(R)-(3-Vinyl-5-hexen-1-yl)benzene (3aa)}

The product 3aa was purified by flash chromatography on silica gel (hexane) (178.9 mg, $0.96 \mathrm{mmol}, 80 \%$ isolated yield from (Z)-2a).

(S)-(2-Vinyl-4-penten-1-yl)benzene (3ab)

The product 3ab was purified by flash chromatography on silica gel (hexane) (15.9 mg, $0.09 \mathrm{mmol}, 62 \%$ isolated yield from $\mathbf{2 b}$ ).

(S)-5-(2-Vinyl-4-penten-1-yl)benzo[d][1,3]dioxole (3ac) 
The product 3ac was purified by flash chromatography on silica gel (5\% $\mathrm{Et}_{2} \mathrm{O} /$ hexane) ( $31.5 \mathrm{mg}, 0.14 \mathrm{mmol}, 97 \%$ isolated yield from $2 \mathrm{c}$ ).

\section{(R)-4-Vinyl-1-dodecene (3ad)}

The product 3ad was purified by flash chromatography on silica gel (hexane) (24.7 $\mathrm{mg}, 0.12 \mathrm{mmol}, 85 \%$ isolated yield from $\mathbf{2 d}$ ).

\section{(R)-Hexa-1,5-dien-3-ylcyclohexane (3ae)}

The product 3ae was purified by flash chromatography on silica gel (pentane) (14.6 mg, $0.09 \mathrm{mmol}$, 59\% isolated yield from $2 \mathrm{e}$ ).

\section{(R)-2-\{[2-Vinyl-4-penten-1-yl]oxy\}tetrahydro-2H-pyran} (Diastereomeric ratio 1:1)

The product 3af was purified by flash chromatography on silica gel (0$2 \%$ EtOAc/hexane) (24.3 mg, $0.12 \mathrm{mmol}, 83 \%$ isolated yield from $\mathbf{2 f}$ ).

\section{(R)-\{[(2-Vinyl-4-penten-1-yl)oxy]methyl\}benzene (3ag)}

The product 3ag was purified by flash chromatography on silica gel (0-1\% EtOAc/hexane) $(22.8 \mathrm{mg}, 0.11 \mathrm{mmol}, 75 \%$ isolated yield from $\mathbf{2 g})$.

\section{(R)-tert-Butyldimethyl[(2-vinylpent-4-en-1-yl)oxy]silane (3ah)}

The product 3ah was purified by flash chromatography on silica gel (0-1\% EtOAc/hexane) (26.6 mg, $0.12 \mathrm{mmol}, 78 \%$ isolated yield from $\mathbf{2 h}$ ).

\section{(R)-2-Vinyl-4-penten-1-yl Pivalate (3ai)}

The product 3ai was purified by flash chromatography on silica gel (0$2 \% \mathrm{EtOAc} / \mathrm{hexane})(20.6 \mathrm{mg}, 0.11 \mathrm{mmol}, 70 \%$ isolated yield from $\mathbf{2 i})$.

\section{(R)-2-Vinyl-4-penten-1-yl 4-Methoxybenzoate (3aj)}

The product 3aj was purified by flash chromatography on silica gel (0$2 \%$ EtOAc/hexane) (31.2 mg, $0.13 \mathrm{mmol}, 85 \%$ isolated yield from $\mathbf{2 j}$ ).

\section{(R)-2-Vinyl-4-penten-1-yl 4-(Trifluoromethyl)benzoate (3ak)}

The product 3ak was purified by flash chromatography on silica gel (0-2\% Et0Ac/hexane) ( $25.9 \mathrm{mg}, 0.09 \mathrm{mmol}, 61 \%$ isolated yield from $\mathbf{2 k}$ ).

\section{(R)-2-Vinyl-4-penten-1-yl 4-Bromobenzoate (3al)}

The product 3al was purified by flash chromatography on silica gel (0$2 \%$ EtOAc/hexane) (28.8 mg, $0.10 \mathrm{mmol}, 65 \%$ isolated yield from $2 \mathrm{I}$ ).

\section{(R)-2-Vinyl-4-penten-1-yl 4-(Dimethylamino)benzoate (3am)}

The product 3am was purified by flash chromatography on silica gel (0-5\% EtOAc/hexane) (34.0 mg, $0.13 \mathrm{mmol}, 87 \%$ isolated yield from 2m).

(R)-1-Benzyl 4-(2-Vinyl-4-penten-1-yl)piperidine-1,4-dicarboxylate (3ap)

The product 3ap was purified by flash chromatography on silica gel (5-10\% EtOAc/hexane) $(43.0 \mathrm{mg}, 0.12 \mathrm{mmol}, 80 \%$ isolated yield from 2p).

\section{(R)-tert-Butyldimethyl[(4-vinyl-6-hepten-1-yl)oxy]silane (3aq)}

The product 3aq was purified by flash chromatography on silica gel (0-1\% EtOAc/hexane) (29.8 mg, $0.12 \mathrm{mmol}, 78 \%$ isolated yield from $\mathbf{2 q}$ ).

\section{(R)-4-Vinyl-6-hepten-1-yl 4-Methylbenzenesulfonate (3ar)}

The product 3ar was purified by flash chromatography on silica gel (0-5\% Et0 Ac/hexane) ( $38.7 \mathrm{mg}, 0.13 \mathrm{mmol}, 88 \%$ isolated yield from $2 \mathrm{r}$ ).

tert-Butyldimethyl[[(2S,3S)-3-vinyl-5-hexen-2-yl] oxy]silane (3as)

The product 3as was purified by flash chromatography on silica gel (0-2\% Et0 Ac/hexane) $(22.2 \mathrm{mg}, 0.09 \mathrm{mmol}, 61 \%$ isolated yield from $2 \mathrm{~s}$ ). Colorless Oil. IR (neat) 664, 772, 830, 910, 994, 1072, 1254, 1361, 1374,
1463, 1472, 1641, 2858, 2887, 2930, 2957, $3078 \mathrm{~cm}^{-1} .{ }^{1} \mathrm{H} \mathrm{NMR}(400 \mathrm{MHz}$ $\left.\mathrm{CDCl}_{3}\right) \delta 0.05(\mathrm{~s}, 6 \mathrm{H}), 0.89(\mathrm{~s}, 9 \mathrm{H}), 1.08(\mathrm{~d}, J=6.4 \mathrm{~Hz}, 3 \mathrm{H}), 1.98-2.12(\mathrm{~m}$, $2 \mathrm{H}$ ), $2.34(\mathrm{~m}, 1 \mathrm{H}$ ), 3.70 (quintet, $J=6.4 \mathrm{~Hz}, 1 \mathrm{H}$ ), 4.95-5.08 (m, 4H), 5.59$5.88(\mathrm{~m}, 2 \mathrm{H}) .{ }^{13} \mathrm{C}$ NMR $\left(100 \mathrm{MHz}, \mathrm{CDCl}_{3}\right) \delta-4.8,-4.3,17.9,20.8,25.7$, $34.5,51.7,70.5,115.2,115.8,137.4,139.1$. HRMS-APCI $(m / z):[\mathrm{M}+\mathrm{H}]^{+}$ calcd for $\mathrm{C}_{14} \mathrm{H}_{29} \mathrm{OSi}$, 241.19822; found, 241.19826. $[\alpha]_{\mathrm{D}} 25+34(c$ 0.37, $\mathrm{CHCl}_{3}$ ). The d.r. (90:10) was determined by ${ }^{1} \mathrm{H}$ NMR analysis of the crude product. The absolute configuration of $\mathbf{3 a s}$ was assigned by consideration of the stereochemical pathway.

(R)-(5-Methyl-3-vinyl-5-hexen-1-yl)benzene (3ba)

The product $3 \mathbf{b a}$ was purified by flash chromatography on silica gel (hexane) (23.1 mg, $0.12 \mathrm{mmol}, 77 \%$ isolated yield from (Z)-2a).

\section{(R)-(5-Methylene-3-vinylheptyl)benzene (3ca)}

The product 3ca was purified by flash chromatography on silica gel (hexane) (16.1 mg, $0.07 \mathrm{mmol}, 50 \%$ isolated yield from (Z)-2a).

\section{(R)-(5-Methylene-3-vinylundecyl)benzene (3da)}

The product 3da was purified by flash chromatography on silica gel (hexane) (35.3 mg, $0.13 \mathrm{mmol}, 87 \%$ isolated yield from (Z)-2a).

\section{(R)-(2-Methylene-4-vinylhexane-1,6-diyl)dibenzene (3ea)}

The product 3ea was purified by flash chromatography on silica gel (0-1\% Et20/hexane) (24.7 mg, $0.08 \mathrm{mmol}, 59 \%$ isolated yield from (Z)2a).

\section{(R)-(4-Methyl-1,5-hexadien-2-yl)benzene (3ft)}

The product $\mathbf{3 f t}$ was purified by flash chromatography on silica gel (hexane) $(23.0 \mathrm{mg}, 0.13 \mathrm{mmol}, 89 \%$ isolated yield from $\mathbf{2 t}$ ). The isolated branched product (3ft) was contaminated with a trace amount of the linear product.

\section{(1R,2R)-2-Allyl-3-cyclopenten-1-yl Diethyl Phosphate (3au)}

The product 3au was purified by flash chromatography on silica gel (20$50 \% \mathrm{EtOAc} /$ hexane) (25.1 mg, $0.10 \mathrm{mmol}, 64 \%$ isolated yield from $\mathbf{2 u}$ ).

\section{(1R,2R)-2-Allyl-3-cyclohexen-1-yl Diethyl Phosphate (3av)}

The product 3av was purified by flash chromatography on silica gel (20-50\% EtOAc/hexane) (21.3 mg, $0.08 \mathrm{mmol}, 52 \%$ isolated yield from 2v).

\section{Acknowledgment}

This work was supported by Grants-in-Aid for Scientific Research (B) (No. 15H03803), JSPS, to H.O. and by CREST and ACT-C, JST, to M.S

\section{Supporting Information}

Is there Supporting Information to be published? Click here to indicate YES or NO (text and links will be updated prior to publication).

\section{References}

[1] Breitmaier, E. Terpenes: Flavors, Fragrances, Pharmaca Pheromones; Wiley-VCH: Weinheim, 2006. See also refs 5-7, 9 and references therein.

[2] a) van Tamelen, E. E.; Schwartz, M. A. J. Am. Chem. Soc. 1965, 87, 3277.; b) Stork, G.; Grieco, P. A.; Gregson, M. Tetrahedron Lett., 1969, 1393.; c) Grieco, P. A.; Masaki, Y. J. Org. Chem., 1974, 39, 2135.; d) Negishi, E.; Valente, L. F.; Kobayashi, M. J. Am. Chem. Soc 1980, 102, 3298.; e) Negishi, E.; Liou, S-Y.,;Xu, C.; Huo, S. Org. Lett. 2002, 4, 261.

[3] For selected papers, see: a) Trost, B. M.; Keinan, E. Tetrahedron Lett. 1980, 21, 2595.; b) Godschalx, J.; Stille, J. K. Tetrahedron Lett. 1980, 21, 2599.; c) Nakamura, H.; Bao, M.; Yamamoto, Y. Angew. 
Chem. 2001, 113, 3308.; Angew. Chem., Int. Ed. 2001, 40, 3208.; d) Karlström, A. S. E.; Bäckvall, J.-E. Chem. Eur. J. 2001, 7, 1981.; e) Jimeńez-Aquino, A.; Flegeau, E. F.; Schneider, U.; Kobayashi, S. Chem. Commun. 2011, 47, 9456.; f) Yuan, Q.; Yao, K.; Liu, D.; Zhang W. Chem. Commun. 2015, 51, 11834.

[4] Diner, C.; Szabo', K. J. J. Am. Chem. Soc. 2017, 139, 2.

[5] a) Zhang, P.; Brozek, L. A.; Morken, J. P. J. Am. Chem. Soc. 2010, 132, 10686.; b) Zhang, P.; Le, H.; Kyne, R. E.; Morken, J. P. J. Am. Chem. Soc. 2011, 133, 9716.; c) Brozek, L. A.; Ardolino, M. J.; Morken, J. P. J. Am. Chem. Soc. 2011, 133, 16778.; d) Ardolino, M. J.; Morken, J. P. J. Am. Chem. Soc. 2014, 136, 7092.; e) Ardolino, M. J.; Morken, J. P. Tetrahedron 2015, 71, 6409.; f) Le, H.; Kyne, R. E.; Brozek, L. A.; Morken, J. P. Org. Lett. 2013, 15, 1432.; g) Wang, X.; Wang, X.; Han, Z.; Wang, Z.; Ding, K. Angew. Chem. 2017, 129, 1136.; Angew. Chem. Int. Ed. 2017, 56, 1116

[6] Hornillos, V.; Pérez, M.; Fañanás-Mastral, M.; Feringa, B. L. J. Am. Chem. Soc. 2013, 135, 2140.

[7] Hamilton, J. Y.; Hauser, N.; Sarlah, D.; Carreira, E. M. Angew. Chem. 2014, 126, 10935; Angew. Chem. Int. Ed. 2014, 53,10759.

[8] Yasuda, Y.; Ohmiya, H.; Sawamura, M. Angew. Chem. 2016, 128, 10974.; Angew. Chem. Int. Ed. 2016, 55, 10816.

[9] For synthesis of chiral 1,5-diene derivatives through $\mathrm{Cu}$-catalyzed enantioselective coupling with diboron, allene and allylic phosphate, see: Meng, F.; McGrath, K. P.; Hoveyda, A. H. Nature 2014, 513, 367.

[10] For reviews on Cu-catalyzed allylic substitutions, see: a) Alexakis, A.; Bäckvall, J. E.; Krause, N.; Pàmies, O.; Diéguez, M. Chem. Rev 2008, 108, 2796.; b) Harutyunyan, S. R.; den Hartog, T.; Geurts, K.; Minnaard, A. J.; Feringa, B. L. Chem. Rev. 2008, 108, 2824. c) Shintani, R. Synthesis 2016, 48, 1087.

[11] For Cu-catalyzed enantioselective allylic substitutions using organoboron reagents and oxygen-functionalized NHC chiral ligands, see: a) Shintani, R.; Takatsu, K.; Takeda, M.; Hayashi, T. Angew. Chem. 2011, 123, 8815.; Angew. Chem. Int. Ed. 2011, 50, 8656.; b) Gao, F.; Carr, J. L.; Hoveyda, A. H. Angew. Chem. 2012, 124 6717.; Angew. Chem. Int. Ed. 2012, 51, 6613.; c) Jung, B.; Hoveyda, A. H. J. Am. Chem. Soc. 2012, 134, 1490.; d) Takeda, M.; Takatsu, K.; Shintani, R.; Hayashi, T. J. Org. Chem. 2014, 79, 2354.; e) Shi, Y.; Jung, B.; Torker, S.; Hoveyda, A. H. J. Am. Chem. Soc. 2015, 137, 8948. See also ref $10 \mathrm{c}$.

[12] For our previous work, see: a) Harada, A.; Makida, Y.; Sato, T.; Ohmiya, H.; Sawamura, M. J. Am. Chem. Soc. 2014, 136, 13932.; b) Ohmiya, H.; Zhang, H.; Shibata, S.; Harada, A.; Sawamura, M. Angew. Chem. 2016, 128, 4855.; Angew. Chem. Int. Ed. 2016, 55, 4777.; c) Hojoh, K.; Ohmiya, H.; Sawamura, M. J. Am. Chem. Soc. 2017, 139, 2184.

[13] For functionalized NHC ligands in asymmetric catalysis, see: a) Hameury, S.; Frémont, P.; Braunstein, P. Chem. Soc. Rev., 2017, 46, 632.; b) Pape, F.; Teichert, J. F. Eur. J. Org. Chem. 2017, 4206.; c) Peris, E. Chem. Rev. 10.1021/acs.chemrev.6b00695
[14] a) Shido, Y.; Yoshida, M.; Tanabe, M.; Ohmiya, H.; Sawamura, M. J. Am. Chem. Soc. 2012, 134, 18573.; b) Hojoh, K.; Shido, Y.; Ohmiya, H.; Sawamura, M. Angew. Chem. 2014, 126, 5054.; Angew. Chem. Int. Ed. 2014, 53, 4954. See also: c) Ohmiya, H.; Yokobori, U.; Makida, Y.; Sawamura, M. J. Am. Chem. Soc. 2010, 132, 2895.; d) Nagao, K.; Yokobori, U.; Makida, Y.; Ohmiya, H.; Sawamura, M. J. Am. Chem. Soc. 2012, 134, 8982.

[15] The use of allyl-9-BBN reagent instead of $\mathbf{1 a}$ under the conditions for Table 1, entry 12 resulted in decreases in both enantioselectivity ( $87 \%$ ee) and product yield $(30 \%)$ but with the exclusive regioselectivity $(\gamma / \alpha>99: 1)$ unchanged.

[16] Scholl, M.; Ding, S.; Lee, C. W.; Grubbs, R. H. Org. Lett. 1999, 1, 953.

[17] The absolute configurations of 3ae and 3ah were determined by comparison of the specific rotations with the values reported previously. See ref 5 a. The absolute configuration of 3au was determined by the Mosher's NMR spectroscopic method. Absolute configurations of the other products were assigned by consideration of the stereochemical pathway. See ref 8 .

[18] The linear $\alpha$-substitution product was $(E)$-isomer.

[19] Data are taken from ref 8 for Eq. 3-6.

[20] Nakamura conducted DFT calculations on the mechanism of the reaction between $[\mathrm{MeCu}(\mathrm{CN}) \mathrm{Li}]$ and allyl acetate to form a square planar four-coordinate $(\gamma-\sigma$-enyl)copper(III) species $[(\pi$-en- $\sigma$ yl)copper(III) complex]. Our mechanistic proposal is in accord with the Nakamura's mechanism, in which the $(\gamma-\sigma$ enyl)copper(III) species is not in equilibrium with the corresponding ( $\alpha$ - $\sigma$-enyl)coppor(III) species; the regioselectivity is determined at the oxidative addition step as a consequence of the asymmetric nature of $\mathrm{MeCuCN}^{-}$. Our proposed mechanism is in accord with the Nakamura's mechanism in that the reaction proceeds through oxidative addition of a cuprate to form the $(\gamma-\sigma$ enyl)copper(III) species followed by reductive elimination. However, the coordination number of $\mathrm{Cu}$ in the allylcopper(III) complex is different by virtue of bidentate coordination of the anionic phenol-NHC chiral ligand (L). The strongly electrondonating NHC coordination should render the $\pi$-en coordination weaker, making the allylic 1,3-Cu-migration in the allylcopper(III) complex more feasible. See: a) Yoshikai, N.; Zhang, S.-L.; Nakamura E. J. Am. Chem. Soc. 2008, 130, 12862. For the effect of a $\sigma$-donor ligand, see: b) Yamanaka, M.; Kato, S.; Nakamura, E. J. Am. Chem. Soc. 2004, 126, 6287.

[21] Rapid formation of a tetravalent borate (B) was confirmed by ${ }^{11} \mathrm{~B}$ NMR spectroscopy. See ref 8.

[22] Zhang, P.; Roundtree, I. A.; Morken, J. P. Org. Lett. 2012, 14, 1416. 
Biosketches



Include photos and short biographical text for all authors. If the photo is of a group of people, specify who is shown where.

Photographs (.jpg or .tif format) must be a minimum of $300 \mathrm{dpi}$ in order to reproduce well in print.

Checklist (have these on hand for manuscript submission in ScholarOne):

- $\quad$ cover letter, including a statement of the work's significance

- full mailing address, telephone and fax numbers, and e-mail address of the corresponding author

- email address for each author

- original Word file

- $\quad$ original graphics files zipped into one zip file

- $\quad$ eye-catching graphical abstract as an individual file

- 5-8 key words

- $\quad$ separate Supporting Information file

- $\quad$ separate zipped Primary Data files including cover sheet (optional) 